\title{
Limitações ao uso de Apis mellifera (Hymenoptera: Apidae) para a polinização dirigida de cultivares: um estudo de caso com a pereira-portuguesa (Pyrus communis L. cv. Rocha)
}

\author{
André Amarildo Sezerino ${ }^{1 *}$ \\ Afonso Inácio Orth ${ }^{2}$ \\ ${ }^{1}$ Empresa de Pesquisa Agropecuária e Extensão Rural de Santa Catarina, Estação Experimental de Caçador. \\ Rua Abílio Franco, 1500, Bom Sucesso, CEP 89500-000, Caçador - SC, Brasil \\ ${ }^{2}$ Universidade Federal de Santa Catarina, Centro de Ciências Agrárias, Departamento de Fitotecnia. \\ Rodovia Admar Gonzaga, 1346, Itacorubi, CEP 88034-001, Florianópolis - SC, Brasil \\ * Autor para correspondência \\ andresezerino@epagri.sc.gov.br
}

Submetido em 24/06/2014

Aceito para publicação em 23/03/2015

\section{Resumo}

A existência de polinizadores capazes de promover a xenogamia é um fator decisivo na produtividade dos pomares. Por ser alógama, devido à autoincompatibilidade gametofítica, a maioria das cultivares europeias de pereiras não produzem frutos com sementes sem a presença de insetos polinizadores. Portanto, o correto manejo e a qualidade das colmeias de Apis mellifera instaladas nos pomares são imprescindíveis para assegurar produções economicamente viáveis. Nesse contexto, objetivou-se avaliar alguns aspectos do sistema de polinização dirigida com A. mellifera que podem interferir decisivamente na eficiência da polinização em um pomar comercial de pereira portuguesa nas condições ecológicas do planalto serrano catarinense, no Sul do Brasil. Foi observada uma baixa visitação de abelhas nas flores de pereira, possivelmente devido a dois fatores: competição floral e densidade insuficiente de colmeias instaladas no pomar. Não foi observada a deposição de pólen nos estigmas, o que confirma a deficiência de polinização na área. A qualidade das colmeias alugadas apresentou diferenças entre os anos, com presença do ácaro Varroa destructor e do microsporídeo Nosema ceranae, os quais podem ter contribuído para o despovoamento das colmeias durante o período de floração e, consequentemente, redução da deposição de pólen no estigma das flores da cultivar produtora de frutos.

Palavras-chave: Abelhas; Apicultura; Nosema ceranae; Pera; Varroa destructor

\section{Abstract}

Limitations to the use of Apis mellifera (Hymenoptera: Apidae) for driven pollination of cultivars: a case study with European pear (Pyrus communis L. cv. Rocha). The existence of pollinators able to promote xenogamy is a decisive factor in the yield of orchards. As it is allogamous, due to gametophytic selfincompatibility, most European pear cultivars do not produce fruits with seeds in the absence of pollinating insects. Therefore, the correct management and quality of Apis mellifera hives installed in the orchards are indispensable to ensure economically viable yields. In this context, we aimed to evaluate some aspects of the driven pollination system with $A$. mellifera that can decisively interfere with pollination effectiveness in a commercial orchard of European pear under the ecological conditions of Santa Catarina's Mountain Plateau, 
in Brazil's South region. We observed low visitation of bees on the pear flowers, possibly due to two factors: floral competition and insufficient density of hives installed in the orchard. No pollen deposition was observed on the stigmas, something which confirms pollination failure in the area. The quality of rented hives showed differences between years, with presence of the mite Varroa destructor and the microsporidian Nosema ceranae, which may have contributed to the depopulation of hives within the flowering period and, consequently, the decreased pollen deposition on the stigmas of flowers of the main fruit-producing cultivar.

Key words: Beekeeping; Bees; Nosema ceranae; Pear; Varroa destructor

\section{Introdução}

Dentre as frutas de clima temperado, a pera é a terceira mais consumida no Brasil, sendo apenas superada pela maçã e a uva (IBGE, 2010). Devido à baixa produção nacional, é a fruta fresca importada em maior quantidade pelo Brasil (FIORAVANÇO, 2007). Em 2011 foram importadas 210.328 toneladas, sendo gastos cerca de US\$204,5 milhões, com o Brasil ocupando o quarto lugar entre os países que mais importam peras no mundo (FAO, 2014). Dentre as cultivares importadas, destacam-se as europeias, tais como: "Williams", "D’Anjou", "Packham's Triumph" e "Rocha" (NAKASU; FAORO, 2003).

Existem no Brasil algumas poucas áreas produzindo peras de alta qualidade, sendo principalmente as cvs. Williams (= Bartlett), Max Red Bartlett, Packham's Triumph, Abate Fetel e Rocha (tipo europeia); Housui, Nijisseiki, Kousui, Atago e Okusankichi (tipo japonesa); e Yali (tipo chinesa) (FAORO, 2009).

A pera "Rocha" ou pera portuguesa é cada vez mais conhecida mundialmente devido às características dos seus frutos, os quais apresentam excelente resistência ao manuseio e ao transporte e uma capacidade de conservação bastante prolongada sem perda da qualidade (SILVA et al., 2005; SOUSA, 2012).

Por ser alógama devido à autoincompatibilidade gametofítica, a maioria das cultivares europeias não produz frutos com sementes sem a presença de insetos polinizadores (BENEDEK, 1996). A polinização anemófila tem pouca ou nenhuma expressão. Para viabilizar a polinização cruzada existe ainda a necessidade do plantio de cultivares polinizadoras que apresentem, além de compatibilidade, período de floração coincidente com a cultivar de interesse econômico. Indica-se na cultura da pereira uma percentagem de plantas polinizadoras entre 10 e $12 \%$ do total das plantas do pomar (FAORO; BRIGHENTI, 2006). Portanto, para superar a barreira da autoincompatibilidade, a transferência do pólen deve ocorrer entre genótipos compatíveis quanto à série alélica " $\mathrm{S}$ " e ser intermediada por insetos polinizadores (FAORO, 2009).

A existência de polinizadores em quantidade e diversidade capazes de promover a xenogamia é um fator decisivo na produtividade dos pomares. Contudo, em diversas áreas do mundo as populações de insetos polinizadores estão sendo reduzidas a níveis abaixo dos quais podem sustentar serviços de polinização adequados em agroecossistemas (FAO, 2004). A riqueza de agentes polinizadores declinou com a intensificação da produção agrícola, provavelmente por degradação do ambiente natural e pelo uso de pesticidas. Devido a isto, a abelha Apis mellifera tornou-se o principal agente executor de serviços de polinização dirigida devido à sua ampla dispersão geográfica, facilidade de manejo, e capacidade de formar grande população de abelhas campeiras que visitam um número relativamente alto de flores de diferentes cultivos em um só dia (PATRON, 2010).

Contudo, mesmo com o manejo racional, a população de abelhas melíferas vem sofrendo perdas ao redor do mundo, acarretando prejuízos no setor produtivo. O fenômeno conhecido como "Colony Collapse Disorder" provocou o desaparecimento da população de abelhas nas colmeias nos Estados Unidos a partir do ano de 2007, se expandiu pelo mundo e, aparentemente, apresenta como principais causas a intoxicação por inseticidas neonicotinoides, a ocorrência de viroses e a infestação pelo microsporídeo Nosema ceranae e pelo ácaro Varroa destructor (COX-FOSTER et al., 2007; DE JONG, 2010).

Devido a diversos gargalos, a cultura da pereira ainda não apresenta uma produção acentuada no Brasil. Questões associadas à falta de adaptação de cultivares às condições edafoclimáticas da região Sul, problemas 
de manejo e, principalmente, problemas associados à polinização e fixação de frutos fazem com que a pereira não apresente uma produção constante, tornando-se um investimento de alto risco e com um longo tempo de retorno econômico. No Brasil, são escassos os trabalhos relativos à interação da cv. Rocha e de suas cultivares polinizadoras com os agentes polinizadores, além da qualidade das colmeias destinadas à polinização de pomares nas condições ecológicas das regiões produtoras.

Neste contexto, este trabalho objetivou avaliar alguns aspectos do sistema de polinização dirigida com A. mellifera que podem interferir decisivamente na eficiência da polinização em um pomar comercial de pereira portuguesa nas condições ecológicas do planalto serrano catarinense.

\section{Material e Métodos}

Os estudos foram desenvolvidos em uma área de produção comercial de pereira "Rocha", localizada no município de Bom Retiro-SC, a uma altitude de $915 \mathrm{~m}$ acima do nível do mar (27०48'44”S; 49²7’06”O), nas safras de 2012/2013 e 2013/2014.

Utilizou-se no estudo a espécie Pyrus communis L., pertencente ao grupo das pereiras europeias, avaliandose as cultivares Rocha, como produtora de frutos, e Packham's Triumph e a pereira japonesa cv. Housui $(P$. piryfolia Nakai), como polinizadoras. $\mathrm{O}$ espaçamento utilizado era o de 4,0m x 1,0m (2.500 plantas.ha-1). As cultivares polinizadoras estavam plantadas em uma fila a cada três filas da cv. Rocha, distanciadas $10 \mathrm{~m}$ uma da outra, totalizando $3,6 \%$ de plantas polinizadoras em relação à produtora.

Durante a floração, foi quantificado em três diferentes períodos do dia $(10,14$ e $16 \mathrm{~h})$ o número de abelhas $A$. mellifera.planta ${ }^{-1}$. minuto ${ }^{-1}$ nas três cultivares, sendo avaliados 30 indivíduos de cada cultivar durante três dias de observação em 2012, e 15 indivíduos de cada cultivar durante oito dias de observação em 2013.

Para determinar a efetividade da polinização mediada por estas abelhas, 12 inflorescências da cultivar Rocha foram ensacadas na pré-antese e, estas, após a abertura floral, desensacadas e observadas. As flores que tiveram uma visita legítima $(\mathrm{N}=12)$ foram coletadas e seus estigmas observados em microscopia eletrônica de varredura (MEV) para a verificação da deposição de grãos de pólen. Também foram coletadas flores $(\mathrm{N}=12)$ sob polinização livre no estádio de queda das pétalas para observar a deposição de pólen nos estigmas. O preparo dos estigmas consistiu na desidratação das amostras em série alcoólica (álcool 80, 90, 96 e $100^{\circ} \mathrm{GL}$ ) e ponto crítico (Leica EM SPD030). Para a caracterização dos grãos de pólen aderidos ao estigma, anteras de flores em estágio de pré antese das cvs. Rocha, Housui e Packham's Triumph foram coletadas, separadas em frascos de vidro e desidratadas em estufa a $38,0 \pm 2,0^{\circ} \mathrm{C}$ por $48 \mathrm{~h}$ para a liberação e secagem dos grãos de pólen. De cada frasco foi retirada uma pequena quantidade de grãos de pólen, os quais foram aspergidos sobre stubs com fita de carbono dupla face. As amostras foram recobertas com ouro em um metalizador Leica EM SCD500, mantidas em dessecador de sílica e, então, observadas em microscópio Jeol JSM - 6390 LV (SEZERINO, 2010). Para a identificação dos grãos de pólen, foram tomadas as medidas do comprimento do eixo polar e do diâmetro equatorial e foi observado o padrão da ornamentação da exina.

A qualidade das colmeias foi determinada segundo Palacios (2011), na qual a classificação da colmeia para realizar a polinização de pomares pode ser considerada boa, regular ou ruim de acordo com o nível populacional (Tabela 1). As colmeias avaliadas $(\mathrm{N}=12)$ foram locadas de um apicultor da região, sendo todas do modelo Langstroth, e introduzidas no pomar em uma densidade de 2 colmeias.ha ${ }^{-1}$.

Também foi observado o número de abelhas campeiras entrando no alvado das colmeias pelo período de um minuto (INFANTE, 2010; PATRON, 2010; PALACIOS, 2011). Foram avaliadas 12 colmeias em três horários distintos (09h30min; 13h30min e 15h45min), sendo quatro dias de observações em cada ano.

O estado sanitário das colmeias destinadas à polinização foi avaliado através da estimativa dos níveis de infestação do ácaro $V$. destructor e do microsporídeo $N$. ceranae, sendo as amostras coletadas dois dias após a chegada das colmeias no pomar. 
TABELA 1: Classificação de colmeias para executarem o serviço de polinização, de acordo com sua população de abelhas adultas, de cria aberta e fechada, e reservas de alimento energético.

\begin{tabular}{|c|c|c|c|c|}
\hline \multirow{2}{*}{ Classificação } & \multirow{2}{*}{$\begin{array}{l}\text { População de } \\
\text { abelhas adultas }\end{array}$} & \multicolumn{2}{|c|}{ Crias } & \multirow{2}{*}{ Mel } \\
\hline & & Aberta & Fechada & \\
\hline Boa & $\begin{array}{c}10 \text { ou mais } \\
\text { favos cobertos } \\
\text { em ambas as } \\
\text { faces }\end{array}$ & 1 favo & 2,5 favos & 2 favos \\
\hline Regular & $\begin{array}{c}\text { 5-9 favos } \\
\text { cobertos em } \\
\text { ambas as faces }\end{array}$ & 0,5 favo & 1,25 favo & 2 favos \\
\hline Ruim & $\begin{array}{c}\text { 1-4 favos } \\
\text { cobertos em } \\
\text { ambas as faces }\end{array}$ & 0,25 favo & 0,5 favo & 2 favos \\
\hline
\end{tabular}

Fonte: Adaptado de Palacios (2011).

O nível de infestação de $V$. destructor em abelhas adultas foi determinado nas duas safras, sendo em cada safra avaliadas 12 colmeias por meio da remoção de aproximadamente 300 abelhas adultas aderentes em três quadros de cada colmeia, as quais foram transferidas para recipientes individualizados contendo etanol $70^{\circ} \mathrm{GL}$ e uma gota de detergente, seguido da contagem de abelhas e de ácaros, determinando, assim, o nível de infestação por colônia (DE JONG et al., 1982).

A incidência de $N$. ceranae foi avaliada de acordo com o protocolo de monitoramento para avaliação de nosemose proposto pelo Laboratorio de Artrópodos da Facultad de Ciencias Exactas y Naturales da Universidad Nacional de Mar del Plata (LABORATÓRIO DE ARTRÓPODOS, 2006). De cada uma das colmeias selecionadas, foi coletada em horário de voo máximo (das $11 \mathrm{~h}$ às $15 \mathrm{~h}$, tempo ensolarado e temperatura superior a $18^{\circ} \mathrm{C}$ ) uma amostra de cerca de 100 abelhas campeiras que estavam retornando para a colmeia e, estas, acondicionadas em uma solução de formol a 4\%. $\mathrm{O}$ número de esporos.abelha ${ }^{-1}$ foi determinado somente em 2012, uma vez que em 2013 diversas colmeias apresentaram quantidade insuficiente de abelhas campeiras e as condições climáticas no momento das coletas não eram adequadas.

$\mathrm{O}$ delineamento experimental para o número de abelhas.planta ${ }^{-1}$. minuto $^{-1}$ e número de abelhas entrando no alvado.minuto ${ }^{-1}$ foi em esquema fatorial inteiramente casualizado (horários x cultivares, e ano x horários, respectivamente). Para o número de favos cobertos com abelhas adultas, com cria aberta, com cria fechada, com mel, a porcentagem de infestação de ácaros $V$. destructor e também o comprimento do eixo polar e do diâmetro equatorial dos grãos de pólen, foi utilizado o delineamento inteiramente casualizado. Os dados foram submetidos à análise de variância e as médias comparadas pelo teste de Tukey a 5\% de significância, utilizando o software ASSISTAT 7.7 ${ }^{\circledR}$.

\section{Resultados}

Foi observada diferença significativa no número de abelhas $A$. mellifera.planta ${ }^{-1} \cdot$ minuto $^{-1}$ entre os diferentes horários avaliados, entre cultivares e entre os horários dentro de cada cultivar no ano de 2012 $(\mathrm{F}=36,87 ;$ g.l. $=809 ; \mathrm{p}<0,001)$ (Tabela 2). A contagem iniciada às $10 \mathrm{~h}$ apresentou a média de abelhas por árvore significativamente superior aos demais horários. O horário de menor visitação de abelhas nas flores foi às 16 h. Na média dos três horários de avaliação, "Rocha"

TABELA 2: Média \pm desvio padrão do número médio de abelhas.planta ${ }^{-1} \cdot$ minuto $^{-1}$ em diferentes períodos do dia nas cvs. Rocha, Housui e Packham's Triumph em Bom Retiro - SC, 2012.

\begin{tabular}{cccccc}
\hline \multirow{2}{*}{ Ano } & \multirow{2}{*}{ Horário } & \multicolumn{3}{c}{ Abelhas.planta $^{-1}$ minuto $^{-1}$} & \multirow{2}{*}{ Média } \\
\cline { 3 - 5 } & & Rocha & Housui & Packham's Triumph $^{*}$ & \\
\hline \multirow{2}{*}{$\mathbf{2 0 1 2}$} & $10 \mathrm{~h}$ & $2,38 \pm 3,18 \mathrm{aB}$ & $0,42 \pm 0,86 \mathrm{aC}$ & $2,98 \pm 2,16 \mathrm{aA}$ & $1,92 \mathrm{a}$ \\
& $14 \mathrm{~h}$ & $1,30 \pm 1,99 \mathrm{bA}$ & $0,38 \pm 0,70 \mathrm{aB}$ & $1,38 \pm 1,54 \mathrm{bA}$ & $1,02 \mathrm{~b}$ \\
& $16 \mathrm{~h}$ & $0,41 \pm 0,82 \mathrm{cA}$ & $0,14 \pm 0,38 \mathrm{aA}$ & $0,17 \pm 0,46 \mathrm{cA}$ & $0,24 \mathrm{c}$ \\
\hline Média & & $1,36 \mathrm{~A}$ & $0,31 \mathrm{~B}$ & $1,50 \mathrm{~A}$ & 1,06 \\
\hline
\end{tabular}

Médias seguidas pela mesma letra minúscula na coluna (diferença entre horários) e maiúscula na linha (diferença entre cultivares) não diferem estatisticamente entre si. Foi aplicado o Teste de Tukey ao nível de 5\% de significância. 
e "Packham's Triumph" não apresentaram diferença significativa ente si, mas estas foram superiores a média observada na cv. Housui.

Entre os diferentes horários do dia, "Housui" foi a única cultivar que não apresentou diferença significativa na visitação de abelhas. Tanto em "Rocha" quanto em "Housui" foi observada uma maior visitação nas flores durante a manhã, a qual diminuiu ao longo do dia. Também foi observado que no período da manhã a cv. Packham's Triumph apresentou a maior média de abelhas por planta, seguida por "Rocha" e, por último, "Housui". Às 14 h, "Packham's Triumph" e "Rocha" não apresentaram diferença significativa entre si, mas foram superiores a "Housui". Já às 16 h, as contagens de abelhas nas flores das três cultivares não apresentaram diferença significativa.

No ano de 2013 também foi observada diferença significativa no número de abelhas $A$. mellifera.planta ${ }^{-1}$. minuto $^{-1}$ entre os diferentes horários avaliados, entre cultivares e entre os horários dentro de cada cultivar ( $F=43,22 ;$ g.l. $=1079 ; p<0,001)$, sendo que as médias do número de abelhas por planta nos horários de avaliação das $10 \mathrm{~h}$ e das $14 \mathrm{~h}$ não apresentaram diferença entre si, mas foram significativamente superiores ao período das $16 \mathrm{~h}$ (Tabela 3).

Foi observado que a cv. Rocha apresentou o maior número de abelhas por planta na média dos três horários, enquanto "Housui" o menor. Assim como em 2012, "Housui" foi a cv. que apresentou a menor média de abelhas por planta em 2013.

No horário das 10 h, "Rocha" também apresentou o maior número médio de abelhas por planta, seguida por
"Packham's Triumph" e por último "Housui". Às 14 h as cvs. Packham's Triumph e Housui não apresentaram diferença significativa entre si, e "Rocha" continuou com a maior média. Já às 16 h, o número de visitas de abelhas por planta não diferiu significativamente entre as cultivares. A observação dos estigmas da pereira "Rocha" após uma visita legítima de $A$. mellifera através de microscopia eletrônica de varredura não evidenciou a deposição de pólen (Figura 1A, B e C). Apenas um grão de pólen com $24,3 \mu \mathrm{m}$ foi observado nos estigmas de flores oriundas de polinização livre (Figura 1D).

Os grãos de pólen das cvs. Rocha, Housui e Packham's Triumph observados em microscopia eletrônica de varredura apresentaram diferença no tamanho e na ornamentação da exina. Observou-se que os grãos de pólen das três cultivares são isolados (mônades), prolatos, isopolares, colpados com três aberturas alongadas que se estendem de um pólo ao outro mas sem se unirem nas extremidades (parassincolpados) (Figura 2A, 2B, 2D, 2E, 2G e 2H).

A ornamentação da exina apresentou diferença entre as cultivares. Em todas as cultivares foi observado que a exina é reticulada. Contudo, na cv. Rocha foi possível observar uma grande quantidade de poros em toda a superfície, exceto nas regiões polares. Já em "Housui" observou-se que os grãos de pólen não apresentam poros (ou apresentam apenas alguns poucos) na região equatorial. A cv. Packham's Triumph apresentou os grãos de pólen com uma porosidade intermediária entre "Rocha" e "Housui", sendo também distribuída somente na região equatorial (Figura $2 \mathrm{C}, 2 \mathrm{~F}$ e 2I).

TABELA 3: Média \pm desvio padrão do número médio de abelhas.planta ${ }^{-1} \cdot$ minuto $^{-1}$ em diferentes períodos do dia nas cvs. Rocha, Housui e Packham's Triumph em Bom Retiro - SC, 2013.

\begin{tabular}{cccccc}
\hline \multirow{2}{*}{ Ano } & \multirow{2}{*}{ Horário } & \multicolumn{3}{c}{ Abelhas.planta $^{-\mathbf{1}}$ minuto $^{-\mathbf{1}}$} & \\
\cline { 3 - 5 } & & Rocha & Housui & Packham's Triumph \\
\hline \multirow{2}{*}{$\mathbf{2 0 1 3}$} & $10 \mathrm{~h}$ & $1,17 \pm 1,45 \mathrm{bA}$ & $0,08 \pm 0,57 \mathrm{aC}$ & $0,84 \pm 0,97 \mathrm{aB}$ \\
& $14 \mathrm{~h}$ & $1,53 \pm 1,70 \mathrm{aA}$ & $0,13 \pm 0,69 \mathrm{aB}$ & $0,33 \pm 0,73 \mathrm{bB}$ \\
& $16 \mathrm{~h}$ & $0,20 \pm 0,46 \mathrm{cA}$ & $0,01 \pm 0,09 \mathrm{aA}$ & $0,12 \pm 0,37 \mathrm{bA}$ & $0,10 \mathrm{~b}$ \\
\hline Média & & $0,96 \mathrm{~A}$ & $0,07 \mathrm{C}$ & $0,43 \mathrm{~B}$ \\
\hline
\end{tabular}

Médias seguidas pela mesma letra minúscula na coluna (diferença entre horários) e maiúscula na linha (diferença entre cultivares) não diferem estatisticamente entre si. Foi aplicado o Teste de Tukey ao nível de 5\% de significância. 
FIGURA 1: Pistilos de flores de pereira "Rocha" após uma visita legítima de Apis mellifera (A, B e C) e sob polinização aberta (D). A) Vista parcial dos pistilos; B) Vista frontal do estigma; C) Detalhe das papilas do estigma e; D) Grão de pólen depositado sobre o estigma (seta).

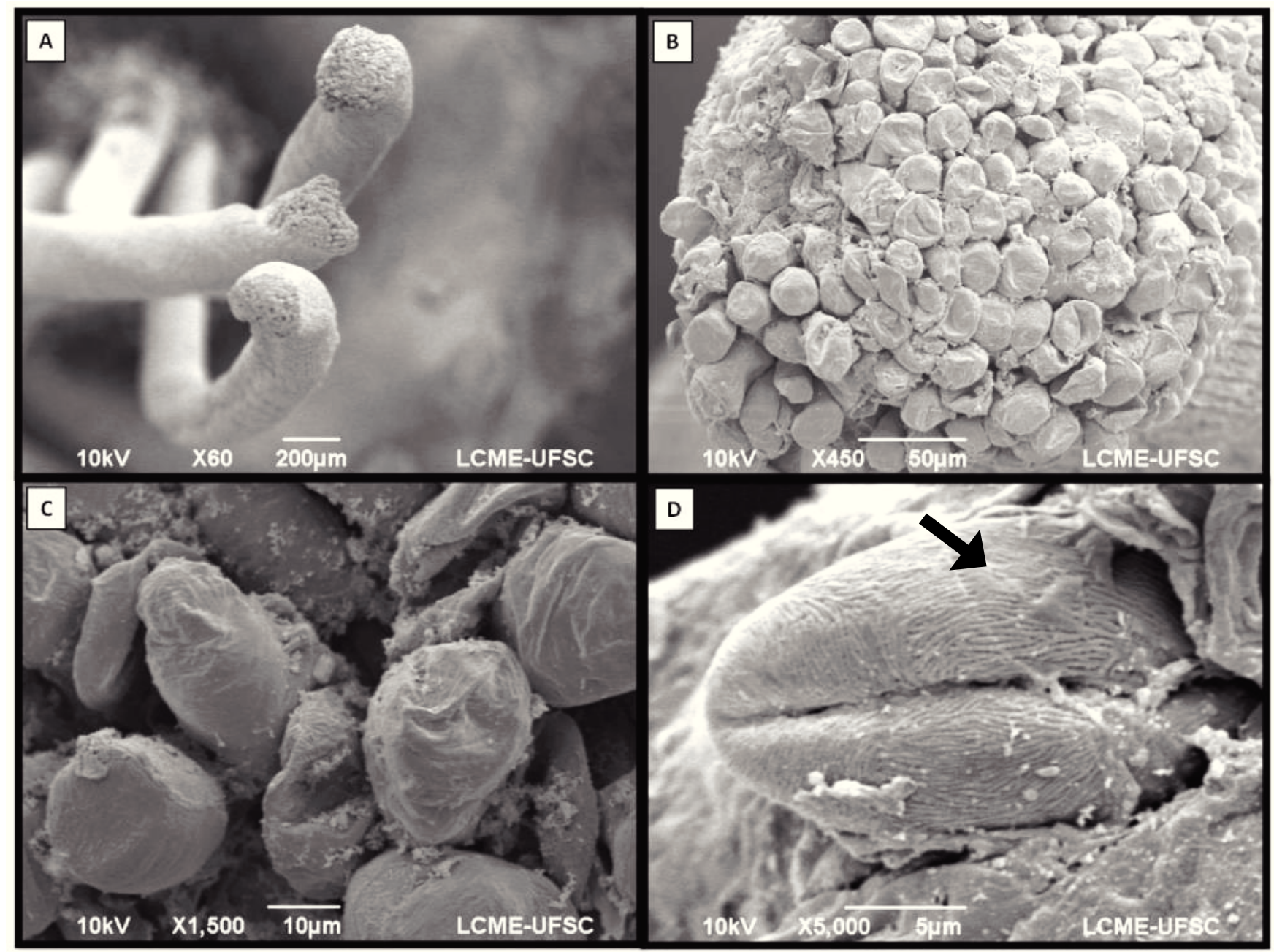

O diâmetro equatorial dos grãos de pólen não apresentou diferença significativa entre as cultivares $(\mathrm{F}=2,70 ;$ g.l. $=18 ; \mathrm{p}=0,09)$ (Tabela 4). Já o comprimento do eixo polar apresentou diferença significativa $(\mathrm{F}=9,69 ;$ g.l.=18; $\mathrm{p}=0,0017)$, sendo o da cv. Housui menor em relação ao das cultivares "Rocha" e "Packham's Triumph" (Tabela 4).

Foi observada diferença significativa na média do número de favos com cria aberta (larvas) $(\mathrm{F}=17,31$; g.l. $=23 ; \mathrm{p}<0,001)$ e favos com mel $(\mathrm{F}=10,68$; g.l. $=23 ; p=0,0037)$ entre 2012 e 2013 . Em ambos os casos as médias foram superiores em 2012. A média do número de favos cobertos com abelhas adultas e com cria fechada (pupas) não apresentou diferença significativa entre os anos avaliados $(\mathrm{F}=4,28 ;$ g.1. $=23 ; \mathrm{p}=0,0508 \mathrm{e}$ $\mathrm{F}=1,357 ; \mathrm{g} .1 .=23 ; \mathrm{p}=0,256$, respectivamente). Os dados referentes ao estado geral de desenvolvimento das colmeias locadas para realizar o serviço de polinização podem ser observados na Tabela 5 . 
FIGURA 2: Grãos de pólen de pereira "Rocha", "Housui" e "Packham’s Triumph" observados em microscopia eletrônica de varredura. $\mathrm{A}, \mathrm{B}$ e C correspondem respectivamente à vista equatorial, polar e o detalhe da ornamentação da exina de "Rocha"; D, E e F correspondem respectivamente à vista equatorial, polar e o detalhe da ornamentação da exina de "Housui"; G, H e I correspondem respectivamente à vista equatorial, polar e o detalhe da ornamentação da exina de "Packham's Triumph".
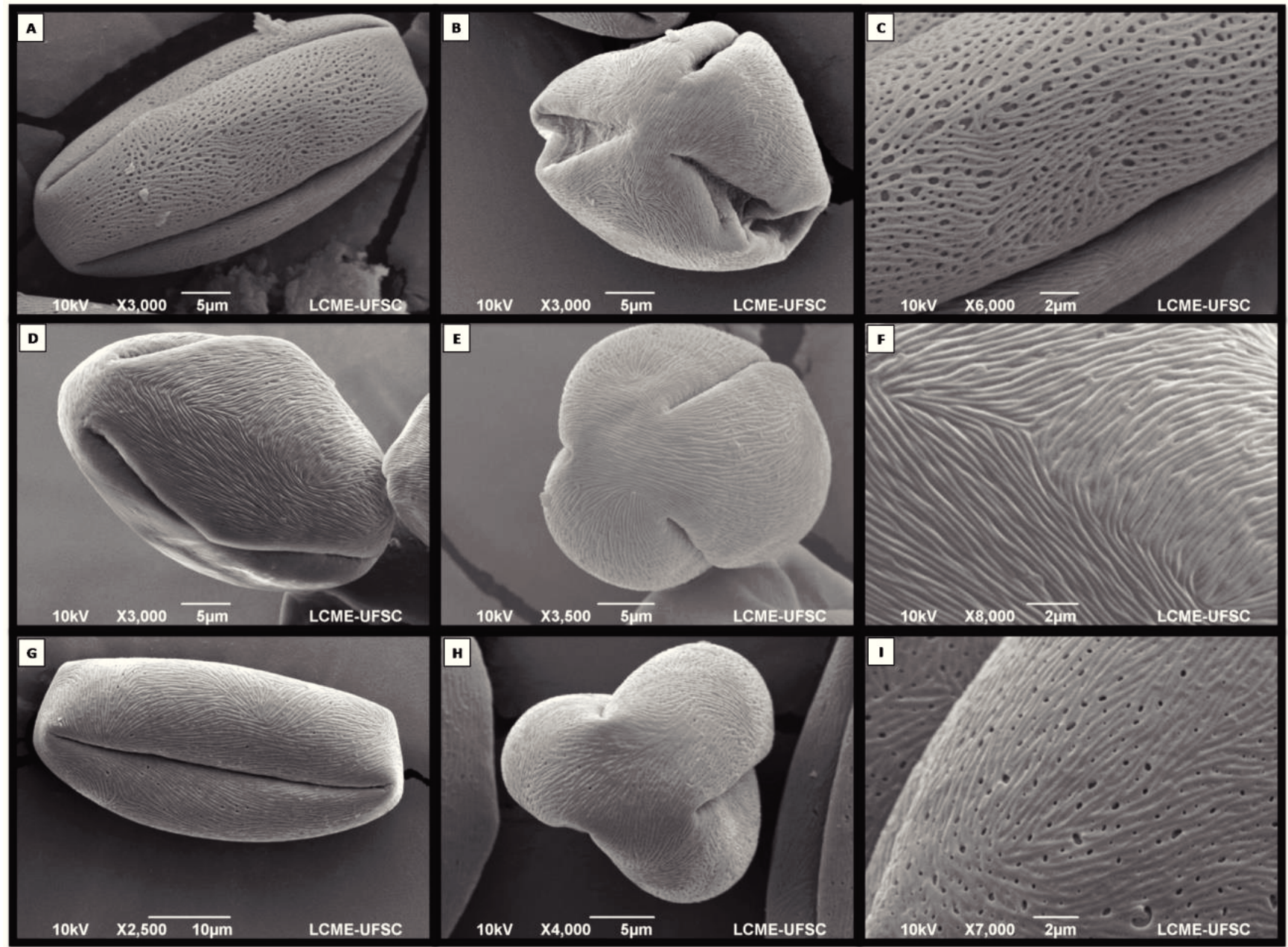

TABELA 4: Média \pm desvio padrão do comprimento do eixo polar e do diâmetro equatorial médio $(\mu \mathrm{m})$ de grãos de pólen das cvs. Rocha, Housui e Packham’s Triumph em Bom Retiro - SC, 2013.

\begin{tabular}{lcc}
\hline \multicolumn{1}{c}{ Cultivar } & Comprimento do eixo polar $(\boldsymbol{\mu m})$ & Diâmetro equatorial $(\boldsymbol{\mu m})$ \\
\hline Rocha & $41,42 \pm 4,40 \mathrm{a}$ & $18,64 \pm 2,10^{\mathrm{ns}}$ \\
Housui & $33,43 \pm 3,80 \mathrm{~b}$ & $20,43 \pm 2,45^{\mathrm{ns}}$ \\
Packham's Triumph & $42,14 \pm 2,96 \mathrm{a}$ & $20,93 \pm 1,20^{\mathrm{ns}}$ \\
\hline
\end{tabular}

As médias seguidas pela mesma letra não diferem estatisticamente entre si. ns= não significativo. Foi aplicado o Teste de Tukey ao nível de $5 \%$ de significância.

TABELA 5: Número médio \pm desvio padrão do número de favos cobertos de abelhas adultas, de cria aberta, de cria fechada e com mel nas colmeias alocadas no pomar para prestação do serviço de polinização em Bom Retiro - SC, 2012 e 2013.

\begin{tabular}{ccccc}
\hline Ano & $\begin{array}{c}\text { № de favos cobertos de } \\
\text { abelhas adultas }\end{array}$ & № de favos com cria aberta & № de favos com cria fechada & № de favos com mel \\
\hline $\mathbf{2 0 1 2}$ & $7,25 \pm 2,53^{\text {ns }}$ & $2,00 \pm 1,04 \mathrm{a}$ & $3,3 \pm 0,98^{\text {ns }}$ & $1,92 \pm 0,79 \mathrm{a}$ \\
$\mathbf{2 0 1 3}$ & $4,50 \pm 3,77^{\text {ns }}$ & $0,55 \pm 0,52 \mathrm{~b}$ & $2,50 \pm 2,26^{\text {ns }}$ & $0,45 \pm 1,04 \mathrm{~b}$ \\
\hline
\end{tabular}

As médias seguidas pela mesma letra não diferem estatisticamente entre si. ${ }^{\text {ns= }}$ não significativo. Foi aplicado o Teste Tukey ao nível de $5 \%$ de significância. 
A atividade de forrageio das abelhas campeiras apresentou diferença significativa na média das avaliações realizadas $(\mathrm{F}=13,12 ; \mathrm{g} .1 .=287 ; \mathrm{p}<0,001)$, sendo em 2012 significativamente superior em relação a 2013 (Tabela 6). Na média dos dois anos, o horário com maior atividade de voo foi às $13 \mathrm{~h} 30 \mathrm{~min}$. Analisando-se individualmente cada ano, é possível observar que, em 2012, o horário de maior forrageio foi às $13 \mathrm{~h} 30 \mathrm{~min}$, enquanto que em 2013 não foi observada diferença significativa entre este horário e o das 09h30min, ambos sendo superiores em relação às $15 \mathrm{~h} 45 \mathrm{~min}$.

A taxa média de infestação de ácaros $V$. destructor nas colmeias avaliadas não apresentou diferença significativa ente os anos de 2012 e 2013 ( $\mathrm{F}=0,284$; g.l. $=23 ; \mathrm{p}=0,599)$. O número de esporos de $N$. ceranae por abelha em 2012 foi de 712.500,0 \pm 459.059,3 (Tabela 7).

\section{Discussão}

Foi observada, em ambos os anos, uma baixa abundância de abelhas $A$. mellifera.planta ${ }^{-1}$.minuto ${ }^{-1}$, sendo a maior visitação de abelhas nas flores das cvs. Rocha e Packham's Triumph observada nos horários das $10 \mathrm{~h}$ e $14 \mathrm{~h}$, contudo com uma contagem muito aquém do recomendado como parâmetro para uma eficiente polinização, o que indica que o número de colmeias por hectare encontrava-se abaixo do necessário, estas não se apresentavam em condições ideais para a polinização e/ ou estava ocorrendo competição floral na área de estudo. Considera-se adequado quatro abelhas por minuto para cada 100 inflorescências (PETRI et al., 2001). Stern et al. $(2004 ; 2007)$ citam que 6-7 abelhas.plantas ${ }^{-1}$. minuto ${ }^{-1}$ é o suficiente para uma adequada polinização em pera, enquanto que para Mayer et al. (1990, apud STERN et al., 2004) 10-15 abelhas.plantas ${ }^{-1}$. minuto ${ }^{-1}$ é satisfatório para esta cultura. Na cv. Housui não foi observada diferença na visitação ente os horários nos dois anos, o que demonstra que suas flores são pouco atrativas mesmo em condições de forrageio favoráveis. Dentre os fatores que podem afetar os índices de visitação de abelhas em flores nos pomares destacam-se o número de flores por cultivar, o volume e a concentração de sólidos solúveis totais no néctar secretado, a oferta de pólen (HOFFMAN; THORP, 1991), a temperatura, a radiação solar, a umidade relativa do ar e a velocidade do vento (FREE, 1993), fatores esses que devem ter afetado a visitação nas flores das três cultivares ao longo do dia.

No Brasil, as recomendações técnicas de densidade de colmeias por hectare são baseadas em estudos conduzidos na década de 1970 em pomares de macieiras "Golden Delicious", "Starkrinson spur" e "Golden

TABELA 6: Média \pm desvio padrão do número de abelhas entrando no alvado.minuto-1 em três diferentes horários de avaliação. Bom Retiro - SC, 2012 e 2013.

\begin{tabular}{|c|c|c|c|c|}
\hline \multirow{2}{*}{ Horário } & \multicolumn{3}{|c|}{ Abelhas entrando no alvado.minuto ${ }^{-1}$} & \multirow{2}{*}{ Média } \\
\hline & 09h30min & $13 \mathrm{~h} 30 \mathrm{~min}$ & $15 \mathrm{~h} 45 \mathrm{~min}$ & \\
\hline 2012 & $50,3 \pm 43,0 \mathrm{aB}$ & $100,8 \pm 48,3 \mathrm{aA}$ & $55,9 \pm 40,7 \mathrm{aB}$ & $68,9 \mathrm{a}$ \\
\hline 2013 & $59,6 \pm 52,8 \mathrm{aA}$ & $59,3 \pm 50,3 \mathrm{bA}$ & $28,4 \pm 32,1 \mathrm{bB}$ & $49,1 \mathrm{~b}$ \\
\hline Média & $54,9 \mathrm{~B}$ & $80,1 \mathrm{~A}$ & $42,1 \mathrm{~B}$ & 59,0 \\
\hline
\end{tabular}

Médias seguidas pela mesma letra minúscula na coluna (diferença entre os anos) e maiúscula na linha (diferença entre horários) não diferem estatisticamente entre si. Foi aplicado o Teste de Tukey ao nível de 5\% de significância.

TABELA 7: Média \pm desvio padrão da porcentagem de ácaros Varroa destructor (relação ácaro.abelha adulta ${ }^{-1}$ ) e do número de esporos do microsporídeo Nosema ceranae.abelha ${ }^{-1}$ em colmeias locadas para polinização do pomar de pereira "Rocha". Bom Retiro - SC, 2012 e 2013.

\begin{tabular}{ccc}
\hline Ano & Varroa destructor $(\%)$ & Nosema ceranae $\left(\right.$ Esporos.abelha $\left.^{-1}\right)$ \\
\hline $\mathbf{2 0 1 2}$ & $1,89 \pm 2,08^{\text {ns }}$ & $712.500,0 \pm 459.059,3$ \\
$\mathbf{2 0 1 3}$ & $1,45 \pm 1,54^{\text {ns }}$ & - \\
\hline
\end{tabular}

ns= não significativo de acordo com a Anova $(\mathrm{p} \geq 0,05 ; \mathrm{F}=0,2843)$. -- Sem avaliação. 
spur" no município de Fraiburgo - SC. A recomendação para aquela época e ainda utilizada atualmente é entre 0,5 e 3,0 colmeias.ha ${ }^{-1}$, sendo que os antigos plantios apresentavam densidades de 600 plantas.ha ${ }^{-1}$, e plantas com uma média de 330 flores (WIESE, 1974). Atualmente, a maior parte dos pomares apresentam plantios em alta densidade $\left(>2.500\right.$ plantas.ha $\left.^{-1}\right)$ e plantas com mais de 500 flores, ou seja, a quantidade de flores por área aumentou significativamente, enquanto a quantidade de abelhas por área mantêm-se a mesma da década de 1970 .

De acordo com Hossein Yeganehrad (comunicação pessoal), em cultivos de maçã no Canadá são utilizadas 7,4 colmeias.ha ${ }^{-1}$ em condições ótimas de forrageio e 12,3 colmeias.ha ${ }^{-1}$ quando há condições meteorológicas adversas e/ou competição floral. Gómez (2010) sugere uma densidade de colmeias para polinização na Argentina de 4-6 colmeias.ha ${ }^{-1}$ na macieira e 7-8 colmeias.ha ${ }^{-1}$ na pereira. Infante (2010) relata que os fruticultores chilenos utilizam cada vez mais uma maior quantidade de colmeias por hectare como forma de assegurar uma boa polinização e obter os máximos rendimentos com frutas de melhor qualidade. Segundo o autor, não é raro que se coloque até 20 colmeias.ha ${ }^{-1}$ em cultivos como de amêndoas e quiuí. Uma vez que na área de estudo utilizou-se a densidade de colmeias seguindo as recomendações da década de 1970 e por se tratar de um pomar em alta densidade, a falta de abelhas campeiras em quantidade suficiente pode ser considerada uma das razões para as baixas contagens de abelhas nas flores.

Outro fator que pode ter interferido na visitação às flores de pereira é a competição floral. Na região do entorno do pomar estudado, a floração das principais espécies silvestres consideradas de alto potencial melífero ocorre entre agosto e novembro (SALOMÉ, 2002), período esse coincidente com a floração da pereira. Foi observado que nos dois anos de avaliações em Bom Retiro, a floração da pereira estava ocorrendo concomitantemente com algumas espécies de plantas nativas, principalmente a bracatinga (Mimosa scabrella Bentham) e o vassourão branco (Piptocarpha angustifolia Dusénex Malme), as quais são consideradas de grande valor apícola e com elevada atratividade para as abelhas. No ano de 2013 também foi observado que a plena floração da pereira "Rocha" coincidiu com o início da floração da macieira em pomares adjacentes à área de estudo, sendo observada uma grande quantidade de abelhas nas flores da macieira em detrimento da pereira.

A principal razão de uma baixa atividade de abelhas em pomares de pereira em Israel é a competição floral do entorno do pomar devido ao florescimento de espécies nativas na mesma época da pereira (STERN et al., 2007). Segundo Free (1993) e Delaplane e Mayer (2000), em todas as espécies frutíferas da família Rosaceae, as abelhas domésticas abandonam as flores alvo em favor de outras espécies mais atrativas que florescem concomitantemente nas proximidades do pomar. Andrade (1996) observou que a quantidade de pólen de pereira recolhido durante as primeiras seis horas após a instalação de duas colmeias num pomar em plena floração diminuía de $85 \%$ para $49 \%$, pois as abelhas abandonavam o pomar em busca de outras fontes de pólen.

O período de introdução de colmeias no pomar em relação ao estágio de florescimento influencia o número de abelhas que visitam o pomar (STERN et al., 2007). Slingerland et al. (2002) recomendam a introdução de colmeias em pomares de pereira com $10-20 \%$ de flores abertas. Entretanto, a introdução de todas as colônias ao mesmo tempo, mesmo no período de plena floração, ainda permite que as abelhas ampliem suas áreas de forrageamento gradualmente, podendo abandonar o pomar quando encontram plantas mais atrativas em floração. Como medida de mitigação, Al Tikrity et al. (1972) sugerem a introdução de colmeias adicionais após uma primeira introdução, uma vez que as abelhas recém introduzidas realizam o forrageamento próximo da colmeia antes de descobrirem as espécies silvestres em floração. Stern et al. (2004) citam que a introdução de 5 colmeias.ha ${ }^{-1}$ em duas vezes (metade com $10 \%$ das flores abertas e o restante na plena floração) promoveu uma maior coleta de pólen de pereira pelas abelhas quando comparado com a introdução de 5 colmeias. $\mathrm{ha}^{-1}$ de uma só vez no início da floração. Salomé e Orth (2012) obtiveram um incremento de 98,8\% na frutificação efetiva de macieiras "Fuji Suprema" em Bom Retiro - SC com a introdução de 6 colmeias.ha $^{-1}$ 
em duas vezes (metade com $20 \%$ de flor aberta e o restante na plena floração) quando comparado com a recomendação técnica vigente que é de no máximo 3 colmeias.ha ${ }^{-1}$ introduzidas com $20 \%$ das flores abertas. Gómez (2010) cita que para a polinização de pomares de pereira na província de Río Negro - Argentina, 50\% das colmeias são levadas ao pomar com $10 \%$ da floração e $50 \%$ na plena floração, visando otimizar o processo de polinização.

Além da baixa visitação nas flores de pereira "Rocha", a não observação da deposição de pólen nos estigmas após uma visita legítima de $A$. mellifera através de MEV confirma a deficiência de polinização na área. O único grão de pólen observado aderido ao estigma, apesar de apresentar a ornamentação da exina semelhante ao pólen das cvs. de pereira deve ser de outra Pomoidea cultivada, uma vez que apresentou o comprimento do eixo polar de aproximadamente $24,3 \mu \mathrm{m}$, sendo que o comprimento médio de grãos de pólen observado nas cvs. Rocha, Housui e Packham's Triumph situaram-se

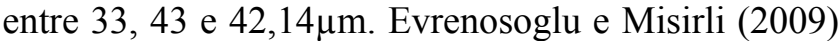
observaram que nos grãos de pólen das cvs. "Ankara" e "Dr. Jules Guyot" (P. communis), o comprimento médio dos grãos de pólen foi de 39,4 $\mu \mathrm{m}$ em "Ankara" e 40,6 $\mu \mathrm{m}$ em "Dr. Jules Guyot", e o diâmetro equatorial de $22,9 \mu \mathrm{m}$ e $22,6 \mu \mathrm{m}$ respectivamente, valores estes muito similares aos das cvs. Rocha, Housui e Packham's Triumph. Adicionalmente, os autores também observaram que os grãos de pólen destas cultivares são prolatos e tricolpados, com poros com menos de $1 \mu \mathrm{m}$ de diâmetro distribuídos irregularmente no tectum, sendo que a cv. Ankara apresentou muito mais poros do que a cv. Dr. Jules Guyot. Tais diferenças também foram observadas nas cvs. Rocha, Housui e Packham's Triumph. O comprimento do eixo polar dos grãos de pólen permitiu diferenciar as cultivares de grupos distintos, uma vez que as pereiras europeias "Rocha" e "Packham's Triumph" (P. communis) não apresentaram diferença significativa entre si, mas foram significativamente superiores à média da cv. Housui. A diferenciação de cultivares do mesmo grupo foi possível somente através da comparação do padrão da ornamentação da exina, especialmente pelas diferenças na porosidade. Portanto, o padrão de ornamentação da exina é uma característica de grande valia na distinção das cultivares. De Grandi-Hoffman et al. (1984) citam que, embora os grãos de pólen de diferentes cultivares de $P$. communis tenham o formato similar, os padrões da exina permitem que sejam facilmente diferenciados.

De acordo com a classificação das colmeias proposta por Palacios (2011), no ano de 2012 as colmeias locadas para a polinização dos pomares encontravam-se em uma situação próxima da ideal, sendo classificadas como "boas". Já em 2013, observou-se uma queda na qualidade das colmeias locadas, as quais foram classificadas como "regulares". Patron (2010) cita que, quando uma colmeia é alugada para polinizar um cultivo, deve cumprir alguns requisitos quanto ao tamanho e desenvolvimento da cria, sendo que para polinização de espécies frutíferas é aceitável quatro a cinco favos com cria sendo $50 \%$ larvas, sete a oito favos cobertos com abelhas adultas e dois favos com mel e pólen. Uma vez que as abelhas colhem o pólen das flores como alimento para as larvas, a quantidade de favos com cria aberta na colmeia é considerado um fator determinante para a coleta deste recurso e, quanto maior a quantidade de larvas, maior é a eficiência desta colmeia como polinizadora (PATRON, 2010). Em 2013, foi observado que, na média dos três horários avaliados e das três cultivares, o número de abelhas $A$. mellifera. planta $^{-1}$.minuto ${ }^{-1}$ foi $54,7 \%$ menor em relação a 2012 , o que pode estar associado ao fato de as colmeias não terem apresentado condições ideais para polinização naquele ano.

Para que uma colmeia seja considerada apta para realizar o serviço de polinização, Infante (2010) e Patron (2010) citam que se deve observar adentrando ao alvado em dias ensolarados entre 50 e 60 abelhas. minuto $^{-1}$. Palacios (2011) cita como adequado para a polinização da cerejeira 50 abelhas entrando.colmeia ${ }^{-1}$. minuto $^{-1}$, enquanto na macieira 75 abelhas entrando. colmeia $^{-1}$. minuto ${ }^{-1}$. No horário das $13 \mathrm{~h} 30 \mathrm{~min}$ do ano de 2012 foi observada uma média de 100,8 abelhas entrando.colmeia ${ }^{-1}$. minuto $^{-1}$, o que indica que atendiam aos requerimentos mínimos de abelhas campeiras recomendados. Contudo, no mesmo ano, devido às baixas contagens de abelhas nas flores de pereira, estas provavelmente estavam forrageando em áreas adjacentes ao pomar. Devido a isto, se recomenda fortemente a 
introdução sequencial das colmeias no pomar, uma vez que na região existe forte competição floral na época do florescimento da pereira. Sugere-se a utilização de pelo menos 6 colmeias.ha ${ }^{-1}$, as quais devem ser introduzidas a metade quando $20 \%$ das flores da pereira estiverem abertas e, a outra metade, na plena floração (SALOMÉ; ORTH, 2012).

É importante que não apenas a quantidade de abelhas adultas e de crias em uma colmeia polinizadora deva ser considerada, mas também seu estado sanitário, sem a constatação de enfermidades provocadas por vários agentes. Cuidados especiais devem ser tomados com patologias causadas pelo ácaro $V$. destructor, e pelo microsporídeo $N$. ceranae, causador da nosemose, devendo as colmeias, direcionadas aos serviços de polinização dirigida, estarem sob monitoramento e controle destes patógenos (INFANTE, 1999).

A taxa média de infestação de ácaros observada em Bom Retiro encontra-se abaixo do considerado preocupante em relação à sanidade apícola. Gramacho e Gonçalves (1994) afirmam que o nível superior a 20\% de infestação é considerado prejudicial às colônias de $A$. mellifera. Além do potencial parasitismo, $V$. destructor tem sido descrito como vetor de diversas doenças, tais como vírus da paralisia aguda, vírus Kashmir e vírus da asa deformada (BAKONYI et al., 2002; CHEN et al., 2004; TENTCHEVA et al., 2004; 2006), as quais podem promover a diminuição da população de abelhas e, consequentemente, a redução da eficiência da polinização. Anastácio et al. (2013) observaram taxas de infestação de $4,18 \%$ na primavera em colmeias no município de Santa Rosa do Sul - SC. Moretto e Leonidas (2003) encontraram taxas de infestação de 2,33\% em Blumenau - SC. Apesar dos níveis baixos de infestação, Carneiro et al. (2007) citam que a introdução de um novo haplótipo do ácaro $V$. destructor no Brasil (haplótipo $\mathrm{K}$ ), ocorrida recentemente, pode estar aumentando a capacidade reprodutiva desse ácaro. Segundo os autores, a porcentagem de fêmeas que invadiram células de crias de operárias e que produziram descendentes fêmeas que podem alcançar o estágio adulto ao emergir das células de operárias foi de 72\% em 2005-2006, comparado com 35\% em 1986-1987. Portanto, o monitoramento das taxas de infestação do ácaro devem se tornar uma atividade de rotina para os apicultores, devendo as colmeias destinadas à polinização de pomares apresentarem baixas percentagens de ácaros no momento de entrada no pomar.

Atualmente, $N$. ceranae encontra-se amplamente difundida em diversos países do mundo (KLEE et al., 2007; CALDERÓN et al., 2008; WILLIANS et al., 2008; HIGES et al., 2009a; INVERNIZZI et al., 2009; WHITAKER et al., 2011; MEDICI et al., 2012). No Brasil, o primeiro relato de infecção por $N$. ceranae foi citado por Klee et al. (2007). Têmse atribuído, com fortes evidências, o declínio da população de abelhas recentemente registrado em alguns países, à presença deste patógeno (HIGES et al., 2006; 2008a; 2009b; 2010; COX-FOSTER et al., 2007; MARTÍN-HERNÁNDEZ et al., 2007; CHEN et al., 2009; PAXTON, 2010). Abelhas infectadas por $N$. ceranae apresentam danos no sistema digestivo, diminuindo o período de vida devido ao estresse energético (MAYACK; NAUG, 2009), ocasionando a redução da população da colmeia e, consequentemente, diminuindo a atividade de polinização (CHEN et al., 2008; HIGES et al., 2008b; BOTÍAS et al., 2013). No Brasil, são praticamente inexistentes trabalhos sobre a flutuação de esporos de $N$. ceranae ao longo do ano em apiários convencionais, e são inexistentes os trabalhos relativos à contagem de esporos em colmeias destinadas à polinização de cultivos. Nos Estados Unidos, a abundância de esporos tem sido utilizada como um indicador da sanidade das colmeias (COX-FOSTER et al., 2007), sendo este um parâmetro de grande valia para a tomada de decisões de manejo sanitário da colmeia. Sarlo (2010) cita que a máxima eficácia do tratamento com o antibiótico fumagilina visando o controle de $N$. ceranae na Argentina é obtida ante a uma abundância de esporos que não supere um milhão de esporos.abelha ${ }^{-1}$. A contagem média de mais de 700.000 esporos. abelha $^{-1}$ nas colmeias alugadas e recém chegadas no pomar em Bom Retiro pode ser um indicativo de que estas, ao longo da floração, poderiam ter sofrido uma diminuição populacional, a qual conjuntamente com a competição floral acarretou em deficiência no serviço de polinização. Portanto, o monitoramento periódico dos esporos e o adequado manejo nutricional e sanitário das colmeias antes da migração para o pomar faz-se 
necessário para que estas se apresentem adequadas ao serviço de polinização.

Os dados apresentados neste trabalho mostraram alguns problemas que induzem um déficit de polinização cruzada na pereira portuguesa e que afetam negativamente a produção em pomares comerciais. Mais estudos sobre o manejo de pomares e de colmeias de A. mellifera devem ser conduzidos buscando formas de mitigar estes problemas e fomentar a produção de frutos em quantidade e qualidade.

\section{Agradecimentos}

Ao Laboratório Central de Microscopia Eletrônica da UFSC pelo auxílio no preparo das amostras e na utilização dos equipamentos relacionados às imagens em microscopia eletrônica de varredura e à Capes pela bolsa de Doutorado cedida ao primeiro autor.

\section{Referências}

AL-TIKRITY, W. S.; BENTON, A. W.; RISIUS, M. L.; CLARKE, W. W. The effect of length of stay of honey bee colony in a crown vetch field on its foraging behaviour. Journal of Apicultural Research, Cardiff, v. 11, p. 51-57, 1972.

ANASTÁCIO, M. D.; SOUZA, T. H. S.; GOULART, L. R.; CARDOSO, D. A. O.; SIlVEIRA, L. G. S.; ARBOITTE, M. Z. Nível de infestação de Varroa destructor africanizadas nas diferentes estações do ano. In: SIMPÓSIO DE INTEGRAÇÃO CIENTÍFICA E TECNOLÓGICA DO SUL CATARINENSE, 2, 2013, Araranguá. Resumos... Araranguá: UFSC, 2013. p. 61-68.

ANDRADE, M. C. M. A. Estudo da utilização de colmeias na polinização da pereira 'Rocha'. 1996. 85 f. Relatório (Trabalho de Fim de Curso de Engenharia Agronómica) - Instituto Superior de Agronomia, Universidade Técnica de Lisboa, Lisboa. 1996.

BAKONYI, T.; FARKAS, R.; SZENDROI, A.; DOBOS-KOVACS, M.; RUSVAI, M. Detection of acute bee paralysis virus by RT-PCR in honey bee and Varroa destructor Field samples: rapid screening of representative Hungarian apiaries. Apidologie, Les Ulis Cedex, v. 33, n. 1, p. 63-74, 2002.

BENEDEK, P. Insect pollination of fruit crops. In: NYÉKI, J.; SOLTÉSZ, M. (Ed.). Floral biology of temperate zone fruit trees and small fruits. 1. ed. Budapest: Akadémiai Kiadó, 1996. p. 287340.

BOTÍAS, C.; MARTÍN-HERNANDÉZ, R.; BARRIOS, L.; MEANA, A.; HIGES, M. Nosema spp. infection and its negative effects on honey bees (Apis mellifera iberiensis) at the colony level. Veterinary Research, Paris, v. 44, n. 25, p. 1-14, 2013.

CALDERÓN, R. A.; SANCHEZ, L. A.; YAÑES, O.; FALLAS, N. Presence of Nosema ceranae in Africanized honeybee colonies in
Costa Rica. Journal of Apicultural Research and Bee World, Cardiff, v. 47, n. 4, p. 328-329, 2008.

CARNEIRO, F. E.; TORRES, R. R.; STRAPAZZON, R.; RAMÍREZ, S. A.; GUERRA JR, J. C. V.; KOLING, D. F.; MORETTO. G. Changes in the reproductive ability of the mite Varroa destructor (Anderson e Trueman) in Africanized honey bees (Apis mellifera L.) (Hymenoptera: Apidae) colonies in southern Brazil. Neotropical Entomology, Piracicaba, v. 36, n. 6, p. 949952, 2007.

CHEN, Y.; EVANS, J. D.; SMITH, I. B.; PETTIS, J. S. Nosema ceranae is a long-present and wide-spread microsporidian infection of the European honey bee (Apis mellifera) in the United States. Journal of Invertebrate Pathology, Riverside, v. 97, p. 186-188, 2008.

CHEN, Y.; EVANS, J. D.; ZHOU, L.; BONCRISTIANI, H.; KIMURA, K.; XIAO, T.; LITKOWSKI, A. M.; PETTIS, J. S. Asymetrical coexistence of Nosema ceranae and Nosema apis in honey bees. Journal of Invertebrate Pathology, Riverside, v. 101, p. 204-209, 2009.

CHEN, Y.; PETTIS, J. S.; EVANS, J. D.; KRAMER, M.; FELDLAUFER, M. F. Transmition of Kashmir bee virus by the ectoparasitic mite Varroa destructor. Apidologie, Les Ulis Cedex, v. 35, n. 4, p. 441-448, 2004.

COX-FOSTER, D. L.; CONLAN, S.; HOLMES, C. S.; PALACIOS, G.; EVANS, J. D.; MORAN, N. A.; QUAN, P.; BRIESE, T.; HORNIG, M.; GEISER, D. M.; MARTINSON, V.; VANENGELSDORP, D.; KALKSTEIN, A. L.; DRYSDALE, A.; HUI, J.; ZHAI, J.; CUI, L.; HUTCHISON, S. K.; SIMONS, J. F.; EGHOLM, M.; PETTIS, J. S.; LIPKIN, W. I. A metagenomic survey of microbes in honey bee Colony Collapse Disorder. Science, Washington, v. 318, n. 5848, p. 283-287, 2007.

DE GRANDI-HOFFMAN, G.; HOOPINGARNER, R. A.; BAKER, K. K. Identification and distribution of cross-pollinating honey bees (Hymenoptera: Apidae) in apple orchards. Environmental Entomology, Lanham, v. 13, p. 757-764, 1984.

DE JONG, D. Desaparecimento das abelhas-Brasil. 2010. Disponível em: <http://www.xibla.com.br/PDF/Davis_de_Jong3. pdf $>$. Acesso em: 3 maio 2013.

DE JONG, D.; ANDREA-ROMA, D.; GONÇALVES, L. S. A comparative analysis of shaking solutions for detection of Varroa jacobsoni on adult honeybees. Apidologie, Les Ulis Cedex, v. 13, n. 3, p. 297-306, 1982.

DELAPLANE, K. S.; MAYER, D. F. Crop pollination by bees. New York: CABI Publishing, 2000. 344 p.

EVRENOSOGLU, Y.; MISIRLI, A. Investigations on the pollen morphology of some fruit species. Turkish Journal of Agriculture and Forestry, Ankara, v. 33, n. 2, p. 181-190, 2009.

FAO. Conservation and management of pollinators for sustainable agriculture - the international response. In: FREITAS, B. M.; PEREIRA, J. O. P. (Ed.). Solitary bees: conservation, rearing and management for pollination. Fortaleza: Imprensa Universitária, 2004, p. 19-25.

FAO. FAOSTAT. 2014. Disponível em: <http://faostat.fao.org/ site/342/default.aspx>. Acesso em: 30 out. 2014.

FAORO, I. D. Biologia reprodutiva da pereira japonesa (Pyrus pyrifolia var. culta) sob o efeito do genótipo e do ambiente. 2009. 219 f. Tese (Doutorado em Recursos Genéticos Vegetais) - 
Faculdade de Agronomia, Universidade Federal de Santa Catarina. 2009.

FAORO, I. D.; BRIGHENTI, E. Pera. In: EPAGRI (Ed.). Avaliação de cultivares para o Estado de Santa Catarina 2006/2007. Florianópolis: Epagri, 2006. p. 124-129.

FIORAVANÇO, J. C. A cultura da pereira no Brasil: situação econômica e entraves para o seu crescimento. Informações Econômicas, São Paulo, v. 37, n. 3, p. 52-60, 2007.

FREE, J. B. Insect pollination of crops. London: Academic Press, 1993. $544 \mathrm{p}$.

GÓMEZ, M. C. Polinización em el Valle Médio de Río Negro. In: BESSONE, J. F. (Ed.). Editorial Campo \& Abejas - Edición especial: Polinización. Buenos Aires: Agencia Periodística CID, 2010. p. 30-33.

GRAMACHO, K. P.; GONÇALVES, L. S. Estudo comparativo dos métodos de congelamento e perfuração de crias para avaliação do comportamento higiênico em abelhas africanizadas. In: CONGRESSO LATINOIBEROAMERICANO DEAPICULTURA, 4, 1994, Cordoba. Resumos... Cordoba, 1994. p. 45.

HIGES, M.; MARTÍN, R.; MEANA, A. Nosema ceranae, a new microsporidian parasite in honeybees in Europe. Journal of Invertebrate Pathology, Riverside, v. 92, p. 93-95, 2006.

HIGES, M.; MARTÍN-HERNÁNDEZ, R.; BOTÍAS, C.; GARRIDO-BAILÓN, E.; GONZÉLES-PORTO, A. V.; BARRIOS, L.; NOZAL, J.; BERNAL, J. L.; JIMÉNEZ, J. J.; PALENCIA, P. G.; MEANA, A. How natural infection by Nosema ceranae causes honeybee colony collapse. Environmental Microbiology, New York, v. 10, n. 10, p. 2659-2669, 2008 b.

HIGES, M.; MARTÍN-HERNÁNDEZ, R.; GARRIDO-BAILÓN, E.; BOTÍAS, C.; MEANA, A. The presence of Nosema ceranae (Microsporidia) in North African honeybees (Apis mellifera intermissa). Journal of Apicultural Research and Bee World, Cardiff, v. 48, n. 3, p. 217-219, 2009a.

HIGES, M.; MARTÍN-HERNÁNDEZ, R.; GARRIDO-BAILÓN, E.; GARCÍA-PALENCIA, P.; MEANA, A. Detection of infective Nosema ceranae (Microsporidia) spores in corbicular pollen of forager honeybees. Journal of Invertebrate Pathology, Riverside, v. 97, p. 76-78, 2008a.

HIGES, M.; MARTÍN-HERNÁNDEZ, R.; GARRIDO-BAILÓN, E.; GONZÁlES-PORTO, A. V.; GARCÍA-PALENCIA, P.; MEANA, A.; NOZAL, M. J.; BERNAL, J. L. Honeybee colony collapse due to Nosema ceranae in professional apiaries. Environmental Microbiology Reports, Hoboken, v. 1, n. 2, p. 110-113, 2009b.

HIGES, M.; MARTÍN-HERNÁNDEZ, R.; MEANA, A. Nosema ceranae in Europe: an emergent type C nosemosis. Apidologie, Les Ulis Cedex, v. 41, n. 3, p. 375-392, 2010.

HOFFMAN, G. G.; THORP, R. The influence of nectar and pollen availability and blossom density on the attractiveness of almond cultivars to honeybees. Acta Horticulturae, Leuven, v. 288, p. 299-302, 1991.

IBGE - INSTITUTO BRASILEIRO DE GEOGRAFIA E ESTATÍSTICA. Pesquisa de orçamentos familiares 2008-2009: aquisição alimentar domiciliar per capita. Rio de Janeiro: IBGE, 2010. s/paginação.

INFANTE, S. C. Importancia del manejo y calidad de lãs colmenas de abejas (Apis mellifera L.) en La polinización delpalto (Persea americana Mill.). Revista Chapingo Serie Horticultura, Chapingo, v. 5, p. 145-150, 1999.

INFANTE, S. C. Polinización de espécies frutales en Chile. In: BESSONE, J. F. (Ed.). Editorial Campo \& Abejas - Edición especial: Polinización. Buenos Aires: Agencia Periodística CID, 2010. p. 27-29.

INVERNIZZI, C.; ABUD, C.; TOMASCO, I. H.; HARRIET, J.; RAMALlO, G.; CAMPÁ, J.; KATZ, H.; GARDIOL, G.; MENDOZA, Y. Presence of Nosema ceranae in honeybees (Apis mellifera) in Uruguay. Journal of Invertebrate Pathology, Riverside, v. 101, p. 150-153, 2009.

KLEE, J.; BESANA, A. M.; GENERSCH, E.; GISDER, S.; NANETTI, A.; TAM, D. Q.; CHINH, T. X.; PUERTA, F.; RUZ, J. M.; KRYGER, P.; MESSAGE, D.; HATJINA, F.; KORPELA, S.; FRIES, I.; PAXTON, R. J. Wide spread dispersal of the microsporidian Nosema ceranae, an emergent pathogen of the western honeybee, Apis mellifera. Journal of Invertebrate Pathology, Riverside, v. 96, p. 1-10, 2007.

LABORATORIO DE ARTRÓPODOS. Protocolo de monitoreo para evaluar nosemosis. Mar Del Plata: Universidad Nacional de Mar del Plata, 2006. 5 p.

MARTÍN-HERNÁNDEZ, R.; MEANA, A.; PRIETO, L.; SALVADOR, A. M.; GARRIDO-BAILÓN, E.; HIGES, M. Out come of colonization of Apis mellifera by Nosema ceranae. Applied and Environmental Microbiology, Washington, v. 73, n. 20, p. 6331-6338, 2007.

MAYACK, C.; NAUG, D. Energetic stress in the honeybee Apis mellifera from Nosema ceranae infection. Journal of Invertebrate Pathology, Riverside, v. 100, p. 185-188, 2009.

MEDICI, S. K.; SARLO, E. G.; PORRINI, M. P.; BRAUNSTEIN, M.; EGUARAS, M. J. Genetic variation and widespread dispersal of Nosema ceranae in Apis mellifera apiaries from Argentina. Parasitology Research, Heidelberg, v. 110, n. 2, p. 859-864, 2012. MORETTO, G.; LEONIDAS, J. M. Infestation and distribution of the mite Varroa destructor in colonies of Africanized bees. Brazilian Journal of Biology, São Carlos, v. 63, n. 1, p. 83-86, 2003.

NAKASU, B. H.; FAORO, I. D. Cultivares. In: NAKASU, B. H.; CENTEllas-QUEZADA, A.; HERTER, F. G. (Ed.). Pêra: Produção. Brasília: Embrapa Informação Tecnológica, 2003. p. 2936.

PALACIOS, P. E. Servicios de polinización com abejas em frutales: parámetros técnicos y de calidad. Revista Actualidad Apícola, Valdivia, v. 3, p. 4-8, 2011.

PATRON, E. Polinización com abejas. In: BESSONE, J. F. (Ed.). Editorial Campo \& Abejas - Edición especial: Polinización. Buenos Aires: Agencia Periodística CID, 2010. p. 4-15.

PAXTON, R. J. Does infection by Nosema ceranae cause "Colony Collapse Disorder" in honeybees (Apis mellifera)? Journal of Apicultural Research, Cardiff, v. 49, n. 1, p. 80-84, 2010.

PETRI, J. L.; LEITE, G. B.; FAORO, I. D. Tratos culturais. In: EPAGRI (Ed.). Nashi, a pêra japonesa. Florianópolis: Epagri/Jica, 2001. p. 195-210.

SALOMÉ, J. A. Levantamento e fenologia de plantas apícolas do estado de Santa Catarina. 2002. 112 f. Dissertação (Mestrado em Recursos Genéticos Vegetais) - Universidade Federal de Santa Catarina, Florianópolis, 2002. 
SALOMÉ, J. A.; ORTH, A. I. Nova visão sobre a polinização dirigida em pomares de macieiras no estado de Santa Catarina. Informativo Zum Zum, Florianópolis, n. 344, p. 12-16, 2012.

SARLO, E. G. Aportes al conocimiento de la natureza y control de la Microsporidiosis causada por Nosema ceranae (Microsporidia, Nosematidae) em las colonias de Apis mellifera (Hymenoptera, Apidae) asentadas em la región sudeste de la província de Buenos Aires, Argentina. 2010. 162 f. Tese (Doutorado) - Universidad Nacional de Mar del Plata, Mar Del Plata, 2010.

SEZERINO, A. A. Ecologia da polinização do mirtilo (Vaccinium ashei Reade cvs. Climax e Powderblue) no município de Bom Retiro, SC. 2010. 83 f. Dissertação (Mestrado em Recursos Genéticos Vegetais) - Universidade Federal de Santa Catarina, Florianópolis, 2010.

SILVA, J. M.; BARBA, N. G.; BARROS, M. T.; TORRESPAULO, A. Rocha, the pear from Portugal. Acta Horticulturae, Amsterdam,v. 671, p. 219-222, 2005.

SLINGERLAND, K.; FISHER, H.; HUNTER, D. Pear cultivars. Ontario: Ontario Ministry of Agriculture and Food, 2002. 8 p.

SOUSA, R. M. Manejo de pomares de pereira 'Rocha'. In: RUFATO, L.; MARCON FILHO, J. L.; MUNIZ, J. N. (Ed.). IV Reunião Técnica da Cultura da Pereira. Lages: Universidade do Estado de Santa Catarina, 2012. p. 22-39.

STERN, R. A.; GOLDWAY, M.; ZISOVICH, A. H.; SHAFIR, S.; $\mathrm{DAG}, \mathrm{A}$. Sequential introduction of honeybee colonies increases cross-pollination, fruit set and yield of Spadona pear (Pyrus communis). Journal of Horticultural Science and Biotechnology, Dundee, v. 79, n. 4, p. 652-658, 2004.
STERN, R. A.; SAPIR, G.; SHAFIR, S.; DAG, A.; GOLDWAY, M. The appropriate management of honeybee colonies for pollination of Rosaceae fruit trees in warm climates. Middle Eastern and Russian Journal of Plant Science and Biotechnology, Isleworth, v. 1, n. 1, p. 13-19, 2007.

TENTCHEVA, D.; GAUTHIER, L.; BAGNY, L.; FIEVET, J.; DAINAT, B.; COUSSERANS, F.; COLIN, M. E.; BERGOIN, M. Comparative analyses of deformed wing virus (DWV) RNA in Apis mellifera and Varroa destructor. Apidologie, Les Ulis Cedex, v. 37, n. 1, p. 41-50, 2006.

TENTCHEVA, D.; GAUTHIER, L.; ZAPPULA, N.; DAINAT, B.; COUSSERANS, F.; COLIN, M. E.; BERGOIN, M. Prevalence and seasonal variations of six bee viruses in Apis mellifera L. and Varroa destructor mite populations in France. Applied and Environmental Microbiology, Washington, v. 70, n. 12, p. 71857191, 2004.

WHITAKER, J.; SZALANSKI, A. L.; KENCE, M. Molecular detection of Nosema ceranae and N. apis from Turkish honey bees. Apidologie, Les Ulis Cedex, v. 42, n. 2, p. 174-180, 2011.

WIESE, H. Normas para atividades de polinização com abelhas em fruticultura. Florianópolis: IASC, 1974. 87 p.

WILliANS, G. R.; SHAFER, A. B. A.; ROGERS, R. E. L.; SHUTLER, D.; STEWART, D. T. First detection of Nosema ceranae, a microsporidian parasite of European honeybees (Apis mellifera), in Canada and Central USA. Journal of Invertabrate Pathology, New York, v. 97, p. 189-192, 2008. 